\title{
Ukośne liczby zespolone w opisie obwodów elektrycznych przy sinusoidalnych i prawie okresowych przebiegach prądów i
}

\begin{abstract}
Streszczenie. W artykule wprowadzono nową definicję tzw „ukośnej liczby zespolonej” w odróżnieniu do dotychczas powszechnie stosowanej definicji „prostokątnych liczb zespolonych”. Są one wektorami 2-D związanymi ze sobą regułą transformacji współrzędnych. Za pomocą takich wektorów reprezentuje się prądy i napięcia sinusoidalne w obwodzie elektrycznym. Natomiast impedancję traktuje sie jako $2 x 2$ - macierzowy operator, który wektorowi prądu przyporządkowuje wektor napięcia. Podano regułę transformacyjną operatora impedancji z prostokątnego do ukośnego układu współrzędnych. Zbadano podstawowe własności algebraiczne wektorów i operatorów w ukośnym układzie współrzędnych i zwrócono uwagę na ich analogie do praw algebry klasycznych liczb zespolonych.
\end{abstract}

Abstract. The article introduces a new definition of the so-called "skew complex number" in contrast to the so far commonly used definition of a "rectangular complex numbers". These numbers can be used to represent the currents and voltages in the electric circuit of the harmonic signals. In the article the terms skew impedance and admittance have been defined. The impedance is treated as $2 \times 2$ - matrix operator that assigns a voltage vector to a current vector. It has been given the rule how to transform an orthogonal impedance operator to the skew coordinate system. It has been also examined the basic algebraic properties of vectors and operators in the skew coordinate system and it has been highlighted analogies to the rules of classical algebra complex numbers. (Skew complex numbers in application to the circuit theory of harmonic and almost harmonic signals).

Słowa kluczowe: liczby zespolone prostokątne i ukośne, transformacje układów współrzędnych, reguły transformacyjne wektorów i operatorów.

Keywords: rectangular and skew complex numbers, transformations of coordinate systems, rules of vector and operator transformations.

\section{Wstęp}

Wiadomo, że monoharmoniczny sygnał o zadanej częstotliwości jest jednoznacznie scharakteryzowany liczbą zespoloną. Sygnał taki może być też scharakteryzowany jednoznacznie dwiema pobranymi próbkami z przebiegu czasowego. Jeżeli próbki te występują w odstępie kątowym $\pi / 2+2 n \pi(n-$ liczba całkowita), to tworzą one parę równoważną odpowiedniej liczbie zespolonej. Jednak gdy próbki te pobrać $w$ innym odstępie kątowym niż $\pi / 2$ (w odstepie nieortogonalnym), to wtedy odpowiadająca im para liczb rzeczywistych ulega pewnemu zniekształceniu tworząc tzw „ukośną liczbę zespoloną". W zbiorze ukośnych liczb zespolonych działają operatory, do których przechodzi się poprzez kongruentne transformacje ukośne. W artykule pokazano $\mathrm{w}$ jaki sposób prądy i napięcia $\mathrm{w}$ obwodach elektrycznych przedstawia się za pomoca ukośnych liczb zespolonych a także jak z użyciem „operatorów ukośnych" wprowadza się pojęcie impedancji i admitancji. Takie postawienie kwestii wydaje się być autorom artykułu nowym, niespotykanym dotąd w literaturze rozwiązaniem matematycznym.

Oprócz tego w tym opracowaniu podejmują się oni odpowiedzi na następujące pytania:

- jaką formę przybierają szeregi potęgowe, wzór Eulera i logarytm dla ukośnych impedancji (admitancji)?

- jak odkształca się wzór Parsevala, iloczyn skalarny, moc czynna, bierna i pozorna?

- jak zmierzyć rezystancję, reaktancję, kondunktancję, susceptancję korzystając $z$ próbek sygnałów sinusoidalnych pobranych w odstępach kątowych nieortogonalnych, tzn $\alpha_{1}-\alpha_{2} \neq \pi / 2+2 n \pi$ ?

- jak zastosować ukośne liczby zespolone do opisu sygnałów wieloharmonicznych, w tym prawie-okresowych i jak uogólnić dla nich wzór Parsevala i wzory na moce czynną i pozorną?

O ile wiadomo autorom samo pojęcie liczby, która nazwali oni "ukośną liczbą zespoloną" nie było dotąd znane, Nie ma też dlatego odpowiedzi na cztery postawione wyżej pytania.
Pojęcie ukośnej liczby zespolonej Sygnał sinusoidalny

$$
\mathrm{y}(\mathrm{t})=|\mathrm{Y}| \cos (\omega \mathrm{t}+\Varangle Y)
$$

scharakteryzowany jest jednoznacznie liczbą zespoloną

$$
\begin{aligned}
& Y=|\mathrm{Y}| e^{j \nless Y}=\mathrm{Y}_{1}+\mathrm{j} \mathrm{Y}_{2}=|\mathrm{Y}| \cos (\varangle Y)+\mathrm{j}|\mathrm{Y}| \sin (\varangle Y) \\
& \text { gdzie: } j=\sqrt{-1}
\end{aligned}
$$

Liczba ta nazywana "prostokątna liczbą zespoloną" tworzy wektor 2-D:

$$
\boldsymbol{Y}=\left[\begin{array}{l}
Y_{1} \\
Y_{2}
\end{array}\right]
$$

Natomiast "ukośna liczba zespolona" jest wektorem utworzonym przez dwie próbki sinusoidy pobrane w momentach kątowych $\alpha_{1}=\omega \mathrm{t}_{1}, \alpha_{2}=\omega \mathrm{t}_{2}$ :

$$
\mathrm{y}_{1}:=\mathrm{y}\left(\mathrm{t}_{1}\right)=|\mathrm{Y}| \cos \left(\alpha_{1}+\Varangle Y\right)
$$$$
\mathrm{y}_{2}:=\mathrm{y}\left(\mathrm{t}_{2}\right)=|\mathrm{Y}| \cos \left(\alpha_{2}+\Varangle Y\right)
$$

Stąd otrzymuje się związek między prostokątną a ukośną liczbą zespoloną

$$
\boldsymbol{y}=\left[\begin{array}{l}
y_{1} \\
y_{2}
\end{array}\right]=\left[\begin{array}{ll}
c_{1} & -s_{1} \\
c_{2} & -s_{2}
\end{array}\right]\left[\begin{array}{l}
Y_{1} \\
Y_{2}
\end{array}\right]=\boldsymbol{T} \boldsymbol{Y}
$$

gdzie:

$\mathrm{c}_{1}=\cos \left(\alpha_{1}\right), \mathrm{c}_{2}=\cos \left(\alpha_{2}\right), \mathrm{s}_{1}=\sin \left(\alpha_{1}\right), \mathrm{s}_{2}=\sin \left(\alpha_{2}\right)$

Transformacja odwrotna układu współrzędnych ma postać

$$
\begin{gathered}
\boldsymbol{Y}=\boldsymbol{T}^{-1} \boldsymbol{y} ; \quad \boldsymbol{T}^{-1}=\frac{1}{\boldsymbol{S}}\left[\begin{array}{cc}
-S_{2} & S_{1} \\
-C_{2} & C_{1}
\end{array}\right] \\
\mathrm{S}=\left|\begin{array}{cc}
C_{1} & -S_{1} \\
C_{2} & -S_{2}
\end{array}\right|=\sin \left(\alpha_{1}-\alpha_{2}\right)
\end{gathered}
$$


Ważną rolę odgrywa operator macierzowy 2x2, który liczbie zespolonej przyporządkowuje jednoznacznie liczbę zespoloną.

Reguła transformacyjna pomiędzy operatorem

$\boldsymbol{y}=\boldsymbol{a} \boldsymbol{x}$

w dziedzinie ukośnych liczb zespolonych a operatorem

$\boldsymbol{Y}=\boldsymbol{A} \boldsymbol{X}$

w dziedzinie liczb prostokątnych okazuje się być liniowym przekształceniem kongruentnym [2]:

$$
A=T^{-1} a T \longrightarrow a=T A T^{-1}
$$

Przykładem jest tu operator jednostki urojonej $j=\sqrt{-1}$, który w zapisie wierszowym działa następująco

$$
\mathrm{Y}_{1}+\mathrm{j} \mathrm{Y}_{2}=\mathrm{j}\left(\mathrm{X}_{1}+\mathrm{j} \mathrm{X}_{2}\right)=-\mathrm{X}_{2}+\mathrm{j} \mathrm{X}_{1}
$$

ale zapis "kolumnowo-macierzowy" przyjmuje postać

$$
\left[\begin{array}{l}
Y_{1} \\
Y_{2}
\end{array}\right]=\left[\begin{array}{cc}
0 & -1 \\
1 & 0
\end{array}\right]\left[\begin{array}{l}
X_{1} \\
X_{2}
\end{array}\right] \text {, w skrócie } \mathrm{Y}=\mathbf{J X}
$$

Tak więc w obu zapisach zauważa sie odpowiedniość

$\boldsymbol{j} \leftrightarrow\left[\begin{array}{cc}0 & -1 \\ 1 & 0\end{array}\right]$

Po transformacji kongruentnej ten operator transformuje się do postaci:

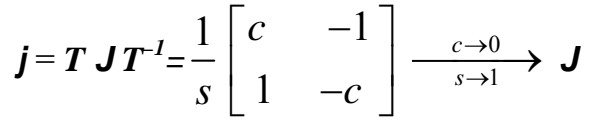

gdzie:

$\mathrm{c}=\cos \left(\alpha_{1}-\alpha_{2}\right), \mathrm{s}=\sin \left(\alpha_{1}-\alpha_{2}\right)$, (odstęp kątowy próbek).

Otrzymany w ten sposób operator - macierz $j$ staje sie ukośny operatorem obrotu - odpowiednikiem prostokątnego $\boldsymbol{J}$ czy też gaussowskiego $\mathrm{j}=\sqrt{-1}$.

Przekształcenie kongruentne zachowuje też wyznacznik:

$$
|\boldsymbol{a}|=\left|\boldsymbol{T} \boldsymbol{A} \boldsymbol{T}^{-1}\right|=|\boldsymbol{A}|
$$

\section{Impedancja i admitancja}

Impedancja, admitancja są operatorami wzajemnie odwrotnymi, które w prostokątnym układzie współrzędnych mają postać macierzy:

$$
\begin{aligned}
& \boldsymbol{Z}=\mathrm{R} \mathbf{1}+\mathrm{X} \boldsymbol{J}=\left[\begin{array}{cc}
R & -X \\
X & R
\end{array}\right] \\
& \boldsymbol{Y}=\mathrm{G} \mathbf{1}+\mathrm{B} \boldsymbol{J}=\left[\begin{array}{cc}
G & -B \\
B & G
\end{array}\right]
\end{aligned}
$$

gdzie: 1 - 2x2 macierz jednostkowa, R, X, G, B rezystancja, reaktancja, konduktancja, susceptancja.

Operator impedancji we "współrzędnych ukośnych", będzie miał postać:

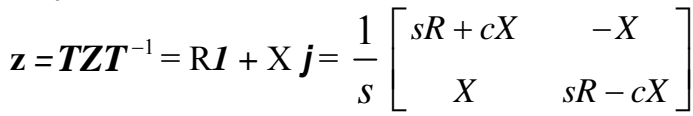

Tak więc jeżeli próbki prądu dwójnika elektrycznego tworzą wektor kolumnowy $\left[i_{1} i_{2}\right]^{\prime}$ to próbki napięcia w tych samych chwilach będzie można otrzymywać ze wzoru

$$
\left[\begin{array}{l}
u_{1} \\
u_{2}
\end{array}\right]=\frac{1}{s}\left[\begin{array}{cc}
s R+c X & -X \\
X & s R-c X
\end{array}\right]\left[\begin{array}{l}
i_{1} \\
i_{2}
\end{array}\right]
$$

Zachodzą też równością dla wyznaczników macierzy:
$\sqrt{|\mathbf{z}|}=\sqrt{|\mathbf{Z}|}=\sqrt{R^{2}+X^{2}}$

Szeregi potęgowe, wzór Eulera, logarytmy

Dla operatora "prostokątnego" zachodzi

(8)

$$
\mathbf{J}^{2}=(-1) \mathbf{1}
$$

Dla operatora "ukośnokątnego" będzie to samo!

$$
\boldsymbol{j}^{2}=\boldsymbol{T} \boldsymbol{J} \boldsymbol{T}^{-1} \boldsymbol{T} \boldsymbol{J} \boldsymbol{T}^{-1}=(-1) \boldsymbol{1}
$$

stąd dla całkowitego $n=0,1,2,3, \ldots$

$$
\begin{gathered}
\boldsymbol{j}^{2 n}=\left(\boldsymbol{j}^{2}\right)^{n}=(-1)^{n} \mathbf{1} \\
\boldsymbol{j}^{2 n+1}=\mathbf{j}^{2 n}=(-1)^{n} \boldsymbol{j}
\end{gathered}
$$

co sprawia że dla skalara rzeczywistego $\phi$ zachodzi:

$$
e^{j \phi}=1 \cos (\phi)+j \sin (\phi)
$$

albo ogólnie, dla macierzy-operatora

$$
\mathbf{z}=\sqrt{|\mathbf{z}|}(\mathbf{1} \cos (\phi)+\boldsymbol{j} \sin (\phi))
$$

Oznacza to, że w ukośnym układzie współrzędnych zachowuje się niezmiennicza postać wzoru Eulera [1]. W formie rozwiniętej macierz ta przyjmuje postać:

$$
\mathbf{z}=\sqrt{|\mathbf{z}|}\left(\begin{array}{cc}
\cos (\phi)+\frac{c}{s} \sin (\phi) & -\frac{1}{s} \sin (\phi) \\
\frac{1}{s} \sin (\phi) & \cos (\phi)-\frac{c}{s} \sin (\phi)
\end{array}\right)
$$

gdy $\mathbf{z}$ jest macierzą-operatorem impedancji, to

$$
\sqrt{|\mathbf{z}|}=\sqrt{R^{2}+X^{2}}, \quad \phi=\operatorname{tg}^{-1}\left(\frac{X}{R}\right)
$$

Logarytm operatora macierzowego $\mathbf{z}=\mathrm{R} \mathbf{1}+\mathrm{X} \boldsymbol{j}=\sqrt{|\mathbf{z}|} e^{j \phi}$ nazywa się macierz $2 \times 2$ :

(13)

$$
\ln (\mathbf{z})=\boldsymbol{1} \ln (\sqrt{|\mathbf{z}|})+\boldsymbol{j} \phi=\left(\begin{array}{cc}
\ln (\sqrt{|\mathbf{z}|})+\frac{c}{S} \phi & -\frac{1}{s} \phi \\
\frac{1}{S} \phi & \ln (\sqrt{|\mathbf{z}|})-\frac{c}{s} \phi
\end{array}\right)
$$

Wzór Parsevala, iloczyn skalarny, moce szynna i bierna, operator sprzężony

Bezpośredni związek między operatorami: prostokątnym $\boldsymbol{J}$ i ukośnym $\boldsymbol{j}$ można też przedstawić w postaci:

$$
\boldsymbol{j}=\mathbf{J} \Delta
$$

Gdzie $\Delta$ zwany będzie "prawostronnym operatorem zniekształcenia" i jest on macierzą symetryczną:

$\Delta=\boldsymbol{J}^{-1} \boldsymbol{j}=\frac{1}{s}\left[\begin{array}{cc}1 & -C \\ -C & 1\end{array}\right]$

Uwzględniając transformację napięć i prądów:

$$
U=T^{-1} u ; \quad I=T^{-1} i
$$

z ukośnego do prostokątnego układu współrzędnych wektorowych, otrzymuje sie wzór na iloczyn skalarny- moc czynną - tzw "czynny wzór Parsevala"[3,4,5]:

$$
U^{\prime} I=\frac{1}{s} u^{\prime} \Delta i=\frac{1}{s} i^{\prime} \Delta u \doteqdot \mathrm{P}
$$

albo w rozpisaniu na współrzędne ma on postać 


$$
U_{1} I_{1}+U_{2} I_{2}=\frac{1}{s^{2}}\left(u_{1} i_{1}+u_{2} i_{2}-\mathrm{c}\left(u_{1} i_{2}\right.\right.
$$

$\left.\left.-u_{2} i_{1}\right)\right)$

Można też udowodnić wzór na moc bierną - tzw. "bierny wzór Parsevala" [3,4,5]:

$$
U^{\prime} \boldsymbol{J} I=\frac{1}{s} u^{\prime} \boldsymbol{J} i=-\frac{1}{s} i^{\prime} \boldsymbol{J} u \doteqdot \mathrm{Q}
$$

który w formie rozwiniętej ma postać:

$-U_{1} I_{2}+U_{2} I_{1}=\frac{1}{S}\left(-u_{1} i_{2}+u_{2} i_{1}\right)$

Dla operatorów impedancji $\mathbf{z}=\mathrm{R} \mathbf{1}+\mathrm{X} \boldsymbol{j}$ i impedancji $\mathbf{y}=\mathrm{G} \mathbf{1}+\mathrm{B} \boldsymbol{j}$ wprowadza się też formy kwadratowe mocy

$$
\begin{aligned}
& P=\frac{R}{2 s} \quad i^{\prime} \Delta i=\frac{G}{2 s} \quad u^{\prime} \Delta u \\
& Q=\frac{X}{2 s} \quad i^{\prime} \Delta i=-\frac{B}{2 s} \quad u^{\prime} \Delta u
\end{aligned}
$$

i wartości skutecznych :

$$
\begin{array}{r}
\|i\|=\sqrt{\frac{1}{2 s} i^{\prime} \Delta i} \\
\|u\|=\sqrt{\frac{1}{2 s} u^{\prime} \Delta u}
\end{array}
$$

Odwrócenie form kwadratowych pozwala wyznaczyć parametry immitancyjne $R, G, X, B$ poprzez pomiary wektorów próbek napięć i prądów sinusoidalnych (zob. rys. 1)

$$
\begin{aligned}
& R=\frac{u^{\prime} \Delta i}{i^{\prime} \Delta i}, X=\frac{u^{\prime} J_{i}}{i^{\prime} \Delta i} \\
& G=\frac{u^{\prime} \Delta i}{u^{\prime} \Delta u}, B=-\frac{u^{\prime} J_{i}}{u^{\prime} \Delta u} \\
& \stackrel{\mathrm{R}}{\longrightarrow} \\
& \stackrel{\mathrm{X}}{\longrightarrow} \mathrm{G}
\end{aligned}
$$

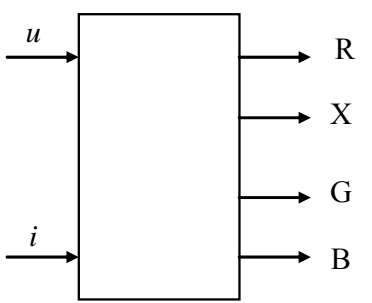

Rys.1. Schemat blokowy układu do pomiaru parametrów immitancyjnych dwójnika

Oprócz prawostronnego operatora zniekształcenia

$\Delta_{P}=\Delta$ definiuje się operator lewostronny $\Delta_{L}$ :

$$
\boldsymbol{j}=\boldsymbol{J} \boldsymbol{\Delta}_{P}=\boldsymbol{\Delta}_{L} \boldsymbol{J}
$$

skąd

$$
\boldsymbol{\Delta}_{P}=\boldsymbol{\Delta}=\mathbf{J}^{-1} \boldsymbol{j} ; \boldsymbol{\Delta}_{L}=\boldsymbol{j}^{-1}=\frac{1}{S}\left[\begin{array}{ll}
1 & C \\
C & 1
\end{array}\right]
$$

co skutkuje tym że $\Delta_{L} \Delta_{P}=\mathbf{1}$

Z użyciem dwóch operatorów zniekształcenia definiuje się operator sprzężony, wychodząc z iloczynu skalarnego :

$$
\text { (zi) }{ }^{\prime} \boldsymbol{\Delta} i=i^{\prime} \mathbf{z}^{\prime} \boldsymbol{\Delta} i=i^{\prime} \mathbf{\Delta} \mathbf{z}^{*} i
$$

skąd

$$
\mathbf{z}^{*}=\boldsymbol{\Delta}^{-1} \mathbf{z} \boldsymbol{\Delta}=\boldsymbol{\Delta}_{L} \mathbf{z}^{\prime} \boldsymbol{\Delta}_{P}
$$

gdzie $z^{*}$ - macierz sprzężona, $z^{\prime}$ - macierz transponowana.
Wynika stąd że

$$
j^{*}=-j
$$

i wynik ten pokrywa sie $z$ analogicznym rezultatem dla prawoskrętnych liczb zespolonych. Zachodzi też:

$$
\frac{1}{2}\left(\mathbf{z}+\mathbf{z}^{*}\right)=\mathrm{R} \mathbf{1} \quad, \quad \frac{1}{2}\left(\mathbf{z}-\mathbf{z}^{*}\right)=\mathrm{X} \mathbf{j}
$$

Ukośne liczby zespolone a sygnały wieloharmoniczne prawie-okresowe

W punkcie tym rozpatrywany będzie sygnał wieloharmoniczny prawie-okresowy zadany szeregiem Fouriera

$$
\mathrm{y}(\mathrm{t})=\frac{1}{\sqrt{2}} \sum_{h} \frac{Y_{h}}{\sqrt{2}} e^{j h t}, \quad Y_{-h}=Y_{h}^{*}
$$

Zakłada się, że sygnał taki próbkowany jest w dwóch chwilach: $t_{1}, t_{2}$. Wówczas punkty kątowe pobrania próbek $\mathrm{tj}$ $\alpha_{1}, \alpha_{2}$, odstęp między nimi $\alpha=\alpha_{1}-\alpha_{2}$, oraz cosinusy i sinusy tych kątów, odpowiednio $\mathrm{c}_{12}, \mathrm{~s}_{12} ; \mathrm{c}, \mathrm{s}$ są funkcjami $h$.

Funkcjami $h$ są również macierze transformacji współrzędnych $\boldsymbol{T}_{h}$ i $\boldsymbol{T}_{h}{ }^{-1}$ :

$$
y_{h}=\boldsymbol{T}_{\boldsymbol{h}} Y_{h} \quad Y_{h}=\boldsymbol{T}_{\boldsymbol{h}}^{-1} y_{h}
$$

Operator J, który sam nie zależy od częstotliwości transformuje się kongruentnie do już zależnego od częstotliwości $\boldsymbol{j}_{\boldsymbol{h}}$ :

$$
\boldsymbol{j}_{\boldsymbol{h}}=\boldsymbol{T}_{\boldsymbol{h}} \boldsymbol{J} \boldsymbol{T}_{\boldsymbol{h}}^{-1}=\frac{1}{S_{h}}\left[\begin{array}{cc}
c_{h} & -1 \\
1 & -c_{h}
\end{array}\right]
$$

Prawostronny operator zniekształcenia, który również będzie zależał od częstotliwości jest macierzą

$$
\boldsymbol{\Delta}_{h}=\mathbf{J}^{-1} \boldsymbol{j}_{h}=\frac{1}{S_{h}}\left[\begin{array}{cc}
1 & -c_{h} \\
-c_{h} & 1
\end{array}\right]
$$

Można wykazać że iloczyn skalarny sygnałów prawieokresowych, który definiowany jest jako granica całki

$$
(u, i)=\left.\frac{1}{T} \int_{-T / 2}^{T / 2} u(t) i(t) d t\right|_{T \rightarrow \infty} \doteqdot \mathrm{P}
$$

we współrzędnych prostokątnych $U_{h}, \quad I_{\mathrm{h}}$ i we współrzędnych ukośnych $u_{h}, i_{h}$ dający moc czynną określony jest wzorem Parsevala:

$$
\begin{gathered}
\mathrm{P}=\frac{1}{2} \sum_{h} U^{\prime}{ }_{h} I_{h}=\frac{1}{2} \sum_{h} \frac{1}{s_{h}} u^{\prime}{ }_{h} \Delta_{h} i_{h}= \\
=\frac{1}{2} \sum_{h} \frac{R_{h}}{s_{h}} i_{h}^{\prime} \Delta_{h} i_{h}=\frac{1}{2} \sum_{h} \frac{G_{h}}{s_{h}} u^{\prime}{ }_{h} \Delta_{h} u_{h}
\end{gathered}
$$

gdzie: $\quad R_{h}, G_{h}$ - funkcje częstotliwościowe rezystancji i konduktancji,

$(\bullet)^{\prime}-$ znak transpozycji 2-D wektora.

Normy - wartości skuteczne określone będą wzorami:

$$
\begin{array}{r}
\|i\|=\sqrt{\frac{1}{2} \sum_{h} \frac{i^{\prime}{ }_{h} \Delta_{h} i_{h}}{s_{h}}} \\
\|u\|=\sqrt{\frac{1}{2} \sum_{h} \frac{u^{\prime}{ }_{h} \Delta_{h} u_{h}}{s_{h}}}
\end{array}
$$

\section{Wnioski}

W artykule podano kilka nowych wyników dotyczących zagadnień identyfikacji pomiarowej drgań jedno- 
harmonicznych i wieloharmonicznych za pomocą dwóch próbek pobranych w określonym odstępie kątowym.

Próbki te pobrane w liczbie po dwie od sygnałów napięcia i prądu dwójnika elektrycznego pozwalają następnie na zidentyfikowanie samego dwójnika pod względem zarówno immitancyjnym (impedancyjno-admitancyjnym) jak i energetycznym. Oznacza to, że za ich pomocą można wyznaczyć operatory immitancji dwójnika przez wyznaczenie ich parametrów rzeczywistych R,X,G,B a także można wyznaczyć iloczyny skalarne napięcia i prądu, a więc moce: $P, Q$ i $|S|$.

Wykazano też, że dwie próbki pobrane w odstępie kątowym ortogonalnym, tj. $\pi / 2+2 n \pi$ identyfikują sinusoidę za pomocą liczby zespolonej wyrażonej wektorem 2-D we współrzędnych prostokątnych. Tę liczbę zespoloną nazywa sie skrótowo "prostokątną". Natomiast gdy próbki pobrane są $w$ odstępie $\alpha \neq \pi / 2+2 n \pi$, wtedy identyfikują one sinusoidę za pomocą wektora 2-D w innym niż prostokątny układzie współrzędnych. Ten właśnie wektor nazywa się w pracy "ukośną liczbą zespoloną".

Prostokątne i ukośne liczby zespolone będące 2-D wektorami odpowiadają sygnałom napięcia i prądu dwójnika elektrycznego. Natomiast impedancja i admitancja dwójnika są operatorami-macierzami $2 \times 2$. Wektory transformują sie wg przekształcenia $\boldsymbol{y}=\boldsymbol{T Y}$, podczas gdy regułą transformacyjną operatorów jest przekształcenie podwójne (kongruentne) : $\boldsymbol{a}=\boldsymbol{T A T}^{-1}$. Okazuje się, że pod względem algebraicznym takie transformowane operatory $2 \times 2$ zachowują sie podobnie do prostokątnych liczb zespolonych, ale też pod pewnymi względami sie od nich różnią.

Kluczem jest w tej kwestii transformata kongruentna operatora jednostki urojonej $j=\sqrt{-1}$, której w zapisie 2-D odpowiada macierz $\mathbf{J}$ wg reguły:

$$
\boldsymbol{J}=\left[\begin{array}{cc}
0 & -1 \\
1 & 0
\end{array}\right] \rightarrow \boldsymbol{j}=\boldsymbol{T} \boldsymbol{J} \boldsymbol{T}^{-1}=\frac{1}{S}\left[\begin{array}{cc}
C & -1 \\
1 & C
\end{array}\right]
$$

gdzie $c^{2}+s^{2}=1$ - współczynniki będące kosinusem i sinusem odchyłki kątowej pobrania próbek sinusoidy.

Operator impedancji dwójnika, złożony z dwóch liczb rzeczywistych $\mathrm{R}, \mathrm{X}$ podlega transformacji

$$
\begin{aligned}
& \mathbf{z}=\mathrm{R} \mathbf{1}+\mathrm{X} \mathbf{J}=\left[\begin{array}{cc}
R & -X \\
X & R
\end{array}\right] \\
& \rightarrow \mathbf{z}=\mathrm{R} \mathbf{1}+\mathrm{X} \mathbf{j}=\frac{1}{s}\left[\begin{array}{cc}
s R+c X & -X \\
X & s R-c X
\end{array}\right]
\end{aligned}
$$

Operatory we współrzędnych ukośnych spełniaja wszystkie prawa matematyczne liczb zespolonych:

- operator $\boldsymbol{j}$ jest oscylującym idempotentem ,

-operatory-macierze komutują w mnożeniu co razem sprawia, że działa dla nich szereg funkcji wykładniczej i wzór Eulera.

Operatory i wektory we współrzędnych ukośnych pozwalają na analizę napięciowo-prądową obwodu elektrycznego z użyciem próbek sinusoidalnych napięć i prądów pobranych w odstępie kątowym innym niż $\pi / 2+2 n \pi$. Natomiast istotne zniekształcenie w ukośnym układzie współrzędnych pojawia się w iloczynie skalarnym napięcia i prądu a więc w wyrażeniach na moc czynną, bierną i pozorną. Pojawiają sie tam prawostronne i lewostronne macierze-operatory zniekształcenia, które wplatają się w środek formy dwuliniowych i kwadratowych. Za pomocą tych form można wyznaczyć bezpośrednio moce $P, Q,|S|$ oraz parametry $R, X, G, B$ tj. poprzez pomiar dwóch próbek napięcia i dwóch próbek prądu w dowolnym, ale tym samym odstępie kątowym.

Główne punkty artykułu posiadające cechy nowości to:

- rozróżnienie napięć i prądów obwodu elektrycznego jako wektorów 2-D od immitancji jako operatorów-macierzy 2x2 - rozszerzenie operatora jednostki urojonej w ukośnokątnym układzie współrzędnych, zbadanie jego właściwości oraz wprowadzenie pojęcia uogólnionej impedancji $\mathrm{R} \mathbf{1}+\mathrm{X} \boldsymbol{j}$

- wprowadzenie operatora-macierzy zniekształcenia $\Delta$ miedzy jednostkami urojonymi w prostokątnym i ukośnym układzie współrzędnych i z jego udziałem zmodyfikowanie iloczynów skalarnych napięcia i prądu w związku z pojęciami mocy $P, Q,|S|$, oraz wzorów do pomiaru parametrów $R, X, G, B$ dwójnika elektrycznego.

W końcu pozostaje pytanie: po co stosować ukośnokątny układ współrzędnych jeżeli można pobrać próbki sygnałów napięcia i prądu $w$ odstępie kątowym $\pi / 2+2 n \pi$ ? Tak może być $w$ przypadku próbkowania pojedynczej sinusoidy, jednak nie jest to możliwe gdy sygnały te składają się $z$ dwóch lub większej liczby harmonicznych o różnych częstotliwościach, a także przy próbkowaniu szeregowym dwóch sygnałów napięcia i prądu. Tę kwestię poruszono w ostatnim punkcie artykułu.

Autorzy: prof. dr hab. inż. Maciej Siwczyński, E-mail: e-3@pk.edu.pl; $d r$ inż. Marcin Jaraczewski, E-mail: jaracz@pk.edu.pl., Politechnika Krakowska, Wydział Inżynierii Elektrycznej i Komputerowej, Katedra Elektrotechniki i Elektroniki ul. Warszawska 24

\section{LITERATURA}

[1] W.Rudin: Functional Analysis, McGraw-Hill Book Company, 1973

[2] J.L.Synge, A.Schild: Rachunek tensorowy, PWN 1964

[3] P.Krzyk: Sposób pomiaru parametrów dwójnika zasilanego napięciem sinusoidalnie zmiennym i parametrów jego pracy, Zgłoszenie patentowe PL 399821, 05.07.2012

[4] M.Jaraczeski, R.Mielnik: Sposobu pomiaru parametrów mocy pobieranej przez dwójnik, zasilany napięciem sinusoidalnie zmiennym o częstotliwości $50 \mathrm{~Hz}$ oraz wartości skutecznej napięcia i prądu tego dwójnika, metoda próbkowania równoległego, Zgłoszenie patentowe 03.12.2015

[5] M.Jaraczeski, R.Mielnik: Sposobu pomiaru parametrów mocy pobieranej przez dwójnik, zasilany napięciem sinusoidalnie zmiennym o częstotliwości $50 \mathrm{~Hz}$ oraz wartości skutecznej napięcia i prądu tego dwójnika, metoda próbkowania szeregowego, Zgłoszenie patentowe 03.12.2015 